\title{
Pacemaker Therapy in Atrial Fibrillation
}

\author{
Shirley Park ${ }^{1^{\star}}$, Paul J. Wang ${ }^{1}$, Paul C. Zei ${ }^{1}$, Henry H. Hsia ${ }^{3}$, Minang Turakhia ${ }^{1,2}$, Marco Perez ${ }^{1}$, and Amin \\ Al-Ahmad ${ }^{1}$ \\ ${ }^{1}$ Cardiac Arrhythmia Service, Stanford University, Stanford, CA \\ ${ }^{2}$ Director, Cardiac Electrophysiology, VA Palo Alto Health Care System, Palo Alto, CA, USA \\ ${ }^{3}$ Health Sciences Clinical Professor, UCSF School of Medicine, San Francisco, CA
}

${ }^{\star}$ Corresponding author: Shirley Park, 300 Pasteur Drive, H2146, Stanford, CA 94305, USA, Tel: 650 723-9363, Fax: 650 725-7568; Email: spark01@stanford.edu

Received Date: July 24, 2013 Accepted Date: August 17, 2013 Published Date: August 19, 2013

Citation: Shirley Park, et al. (2013) Pacemaker Therapy in Atrial Fibrillatio. J Cardio Vasc Med 1: 1-7

\begin{abstract}
There are a number of different roles for pacemaker therapy in the management of Atrial Fibrillation (AF). The most common indication for pacing in AF is to prevent bradycardia in patients with rapid ventricular rates and sinus node dysfunction. Atrioventricular (AV) junction ablation can be an effective alternative therapy for elderly patients or patients with significant medical comorbidities who have highly symptomatic, drug-refractory AF. Ventricular rate regularization is another pacemaker strategy that can decrease the symptoms of AF by pacing near the mean intrinsic ventricular rate during AF. Other pacing algorithms attempt to decrease the incidence of AF by promoting or maintaining sinus rhythm, but the magnitude of this overall effect is modest. Finally, pacemakers can also serve as a diagnostic tool for monitoring frequency of AF and providing information on AF burden, including asymptomatic episodes.
\end{abstract}

Keywords: Permanent Pacing; Atrial Fibrillation; Pacing Algorithms

\section{Introduction}

There are a number of applications for pacemaker therapy in the management of Atrial Fibrillation (AF). The most frequent indication for pacing in $\mathrm{AF}$ is to prevent bradycardia in patients with rapid ventricular response and sinus node dysfunction. For elderly patients or patients with significant medical comorbidities who have highly symptomatic, drug-refractory AF, pacemaker implantation and atrioventricular (AV) junction ablation can be an effective alternative therapy. Pacing may also decrease symptoms during atrial fibrillation by regularizing the ventricular rate. Other pacing strategies attempt to decrease AF recurrence, but these algorithms have demonstrated only limited success. Although pacing is generally not considered primary therapy for AF, it may play an important adjunctive role in the management of patients with AF.

\section{AV junction ablation with permanent pacemaker implantation}

AV junction ablation with permanent pacing may be an effective alternative therapy for elderly patients or patients with multiple comorbidities who have drug-refractory AF and poorly tolerated symptoms due to rapid ventricular response. There have been a number of non-randomized studies examining the effect of $\mathrm{AV}$ junction ablation and pacing on outcomes such as Quality of Life (QOL), symptom reduction, cardiac performance, exercise duration, and health care utilization [15]. One meta-analysis looked at 21 mostly non-randomized trials with a total of 1181 patients, all with highly symptomatic, medically refractory atrial tachyarrhythmias (97\% AF). The analysis demonstrated significant improvement after ablation in cardiac symptom scores (e.g., palpitations, rest and effort dyspnea, exercise intolerance), QOL measures, health care utilization, ejection fraction, and exercise duration. The only outcome that did not reach statistical significance was fractional shortening, although there was a trend toward improvement[1]. 
There are a limited number of randomized trials comparing AV junction ablation with ventricular pacing to either medical therapy alone or pacemaker therapy without ablation [69]. One short-term study randomized 23 patients with chronic AF or flutter to either AV junction ablation with pacemaker implantation or pacemaker implantation alone. At 15 day follow-up, there was a significant reduction in palpitations, effort dyspnea, exercise intolerance, and asthenia, or loss of strength, in the ablation group. Brignole, et al [6] published two randomized trials with longer follow-up periods $[7,8]$. The first looked at patients with paroxysmal AF and the second with chronic AF and heart failure. They were randomized to AV junction ablation with ventricular pacing versus medical therapy alone. In the first trial with paroxysmal AF, the patients received DDDR mode-switch pacing, while the chronic AF patients received VVIR pacing. Follow-up was 6 and 12 months respectively. There was a significant improvement in palpitations, effort dyspnea, exercise intolerance, and easy fatigue in both studies. In the first trial with paroxysmal AF, there was also significant improvement in a heart failure questionnaire. However, more patients in the ablation arm had recurrences of AF due to discontinuation of antiarrhythmic therapy [8]. In chronic AF, there was no improvement in the heart failure questionnaire or in other measures of cardiac performance, including NYHA functional class, ejection fraction, and activity scale. This is in direct contrast to data from the non-randomized trials described above, which showed significant improvement in ejection fraction and other measures of cardiac performance [1-5]. One proposed explanation is that the improvement in cardiac function observed in the nonrandomized studies was due to rate control alone, regardless of the mode of therapy [7].

Although there can be benefits with AV junction ablation and ventricular pacing, there are also some drawbacks to this mode of therapy. First, the procedure is irreversible and leaves the patient pacer-dependent for life. Second, it does not obviate the need for anticoagulation [3-5]. Third, right ventricular (RV) pacing has been shown to induce ventricular dyssynchrony and may worsen Left Ventricular (LV) function and mitral regurgitation in patients with LV systolic dysfunction[10].

There is a growing body of literature supporting the use of Cardiac Resynchronization Therapy (CRT) in patients with LV dysfunction receiving AV junction ablation. Doshi et al. [11] randomized 184 patients undergoing AV junction ablation to either RV pacing versus CRT. The primary outcomes were 6-minute walk test, QOL measures, and ejection fraction. Both groups showed improvement over baseline, but there was a significantly greater improvement in 6-minute walk test and ejection fraction with CRT versus RV pacing, particularly in the subgroup of patients with LV dysfunction or NYHA Class II or III heart failure. AVERT-AF is an ongoing prospective, multi-center, double-blind, randomized controlled trial that will investigate the use of CRT after AV junction ablation in patients with chronic AF and LV dysfunction, regardless of QRS duration. Inclusion criteria include permanent AF for $>90$ days and at least one attempt at cardioversion, Class I or II indication for ICD, LVEF $\leq 35 \%$, NYHA II or III heart failure, and maximally tolerated heart failure and rate control therapy. Patients will be randomized to either pharmacologic rate control with single-chamber ICD versus AV junction ablation and biventricular ICD. The primary endpoint will be change in exercise capacity, with secondary endpoints including QOL score, NYHA status, and LVEF [12].

BLOCK-HF is a recently published prospective, multi-center, double-blind, randomized controlled trial comparing RV pacing versus CRT in patients with AV block and a pacing indication, NYHA I, II, or III heart failure, and LVEF $\leq 50 \%$. All patients received a CRT device (either pacemaker or defibrillator if ICD criteria were met) and were randomized to standard $\mathrm{RV}$ or biventricular pacing. The CRT group had a significant reduction in the composite endpoint of time to death from any cause, heart failure urgent care visit requiring intravenous therapy, or a $\geq 15 \%$ increase in LV end-systolic volume index [13].

PABA-CHF randomized 81 patients with symptomatic AF and low $\mathrm{EF}(<40 \%)$ to pulmonary vein isolation versus AV node ablation with biventricular pacing. Patients in the pulmonary vein isolation group had a significantly better composite primary endpoint, which included performance on a heart failure questionnaire, 6-minute walk test, and change in ejection fraction [14].

Lastly, there is a rare incidence of polymorphic ventricular tachycardia and sudden death following AV junction ablation [3-5,10,15]. After AV junction ablation, there is thought to be an increased risk of bradycardia-dependent arrhythmias, particularly torsades de pointes. This risk can be minimized by programming the lower rate of the pacemaker at 70-90 bpm for the first month after ablation $[3,5,10]$. By six years post therapy, however, the mortality rate is similar between AV junction ablation versus medical therapy [15].

In summary, clinical trials of AV junction ablation with ventricular pacing have demonstrated efficacy in improving symptoms and quality of life, but are equivocal with regards to improving cardiac function. In general, the use of AV junction ablation with ventricular pacing is reserved for predominantly elderly patients or those with significant comorbidities who are not candidates for antiarrhythmic medication, have failed rhythm control with antiarrhythmic agents, and are not candidates for ablation of atrial fibrillation.

\section{Pacing to regulate ventricular rate during AF}

Because of the aforementioned drawbacks of AV junction ablation with ventricular pacing, other approaches have been investigated to utilize ventricular pacing alone without $\mathrm{AV}$ junction ablation. These strategies primarily target ways to minimize the irregularity of ventricular response during AF. AF can have a number of deleterious effects on cardiac hemodynamics, including loss of atrial contraction, valvular regurgitation, rapid ventricular rate, and irregular ventricular response [16,17]. Daoud et al. [18] measured cardiac output in eleven patients after AV junction ablation during regular and irregular ventricular pacing at the same mean cycle lengths. They found a $12 \%$ decrease in cardiac output during irregular versus regular 
ventricular pacing at the same mean cycle lengths. Clark et al. [17] studied sixteen patients with AF after AV junction ablation and paced them in three modes in random sequence: 1) VVI at 60 beats/minute; 2) VVI at the same average rate as intrinsically conducted AF (102 beats/minute); 3) VVT with pacing triggered by playback of a frequency modulated tape recording of the RV apex electrogram previously recorded during intrinsically conducted AF (102 beats/minute). VVT irregular pacing resulted in decreased cardiac output, increased pulmonary capillary wedge pressure, and increased right atrial pressure compared with VVI pacing at the same average rate.

Given these results, it would follow that patients with AF might benefit from improved regularity, as well as improved rate control. It has been demonstrated that ventricular pacing near the mean heart rate of intrinsically conducted AF can significantly reduce cycle length variability. Intrinsic cycle lengths that are longer than the pacemaker lower rate limit are overdriven by demand pacing, while shorter cycle lengths are minimized due to concealed conduction of the paced beat into the AV node[19].

Utilizing this concept, there have been several Ventricular Rate-Smoothing (VRS) algorithms developed with the goal of reducing cycle length variability. Some examples of VRS algorithms include Dynamic Overdrive Pacing (DOP-VRS), flywheel-VRS, Mean Absolute Difference (MADIFF-VRS), and the adaptive-VRS [20]. Most of these algorithms function by slightly increasing the pacing rate in response to ventricular sensed events, and reducing the pacing rate in response to ventricular paced events [16,20]. Ultimately, these algorithms attempt to pace just fast enough to suppress intrinsic conduction, and have been shown to effectively decrease ventricular cycle length variability in AF with either no change or a slight increase in overall mean ventricular rate [21-25]. An upper rate limit is necessary to prevent the algorithm from escalating to excessive rates (Figure 1).

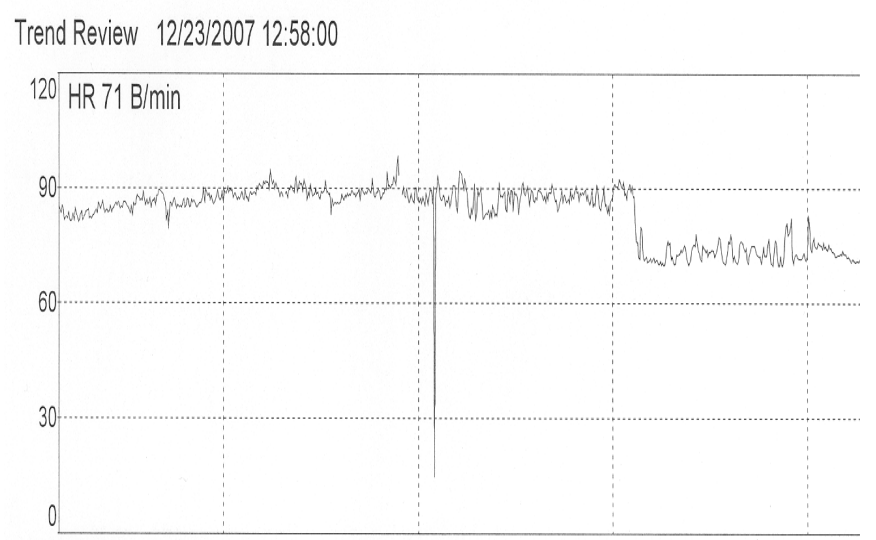

Figure 1: Heart rate trend over 24 hours that shows a patient with persistent AF. Note that the ventricular rate regularization algorithm is initially turned "on" and the average heart rate is around $90 \mathrm{bpm}$. Once this algorithm is turned "off", the average heart rate is in the range of $70 \mathrm{bpm}$.

Clinical outcomes using various VRS algorithms have unfortunately shown equivocal benefit at best. Simpson et al. randomized fourteen AF patients to VRS algorithm on or off and found that there was no improvement in exercise time, oxygen uptake, quality of life scores, or ejection fraction. In fact, three patients had worsening of ejection fraction with the algorithm on, most likely secondary to poorly controlled ventricular rates prior to activation of the algorithm, with subsequent rapidly paced heart rates [21].

The AF SYMPTOMS Study enrolled a total of ninety patients with either paroxysmal or persistent AF across eleven centers. After pacemaker implantation, the subjects were randomized to VRS algorithm on or off. There was a significant reduction in ventricular rate variability without an increase in the mean ventricular rate with VRS-on. However, there was no significant difference in quality of life scores or 6-minute walk distances between VRS-on and VRS-off for both paroxysmal and persistent AF. In patients with persistent AF, there was a significant reduction in frequency of reported symptoms in the VRS-on group, although there was no difference in severity or number of symptoms. This did not hold true for the paroxysmal AF group [22].

Verma et al. [23] studied eleven patients with chronic AF who received VVIR pacemakers prior to AV junction ablation. Before undergoing AV junction ablation, a VRS algorithm was activated which resulted in a significant reduction in cycle length variability without any change in mean heart rate. During VRS pacing, there was a modest improvement in ejection fraction from 31 to 36 percent compared to VRS off. After AV junction ablation, patients had a further improvement in ejection fraction to $44 \%$ while paced at approximately 70 beats/ minute. When the pacing rate was increased to pre-ablation rates (110 beats/minute), however, the ejection fraction decreased to the pre-ablation level of $31 \%$. Some hypothesize that the deleterious effects of RV pacing may offset the benefits of VRS algorithms. To this end, Tse et al. [26,27] conducted two small randomized trials to investigate whether differential site pacing at the RV apex (RVA) versus RV septum (RVS) has any impact on the clinical outcomes of VRS algorithms. The first study randomized 24 patients with permanent AF and symptomatic bradycardia to RVA or RVS pacing. The QRS was significantly narrower with RVS pacing. A VRS algorithm was turned on after 6 months, and the patients assessed at 6 , 12, and 24 months. 6-minute walk test and ejection fraction were comparable at 6 months, however after VRS was turned on, the RVS group had significantly improved 6-minute walk tests at 24 months [26]. RVA pacing was associated with a significant decrease in ejection fraction while the RVS group had relatively preserved ejection fractions at 24 months [26].

The second study by Tse et al. [26] randomized 30 patients with permanent AF and symptomatic bradycardia to RVA versus RVS pacing. All patients underwent cardiopulmonary exercise stress testing with VRS-off and VRS-on. Overall, VRS-on decreased Ventricular Rate (VR) variability and increased peak exercise VR, exercise time, Metabolic Equivalents (METs), and peak oxygen consumption $\left(\mathrm{VO}_{2} \max \right)$. On further analysis, only patients with RVS pacing had significant increases in exercise time, METs, and $\mathrm{VO}_{2}$ max with VRS-on, despite similar changes in peak exercise VR and VR variability compared to RVA pacing [27]. 
These studies suggest that ventricular rate regularization in AF may lead to modest improvements in symptoms and ejection fraction. However greater benefit may be achieved by improving both ventricular rate and regularity (e.g., AV junction ablation with ventricular pacing). It has been shown that the deleterious effect of cycle length irregularity on LV performance is enhanced at faster heart rates [28]. To date, however, there has not been a randomized study directly comparing VRS algorithms to $\mathrm{AV}$ junction ablation with pacing.

In general, the use of VRS algorithms is reserved for patients who continue to have symptoms of AF despite optimal rate control and who already have a pacemaker implanted. Most often these are patients with persistent AF in whom rhythm control with medications or ablation may not be an attractive option. Once activated, a 24-hour monitor or the pacemaker histogram may be useful to monitor the average heart rate.

\section{Atrial Pacing Strategies in AF}

Pacing algorithms for prevention of AF: For patients with paroxysmal AF, there are a number of device-based algorithms to prevent the recurrence of AF. Initiation of AF has been related to Premature Atrial Complexes (PACs), bradycardia, sudden onset, and tachycardia. The idea behind these pacing algorithms is to suppress PACs and reduce the dispersion of atrial refractoriness induced by bradycardia $[3,28]$. There are two categories of prevention algorithms, continuous and triggered. Continuous algorithms pace the atrium faster than the intrinsic atrial rate. Programmable settings can vary the pacing rate, upper therapy rate, and decay rate.

Triggered algorithms will be activated in response to a specific event. There are several different triggered algorithms. PAC suppression attempts to decrease PAC frequency by overdrive suppression. When a PAC is detected, overdrive pacing is initiated at a programmable rate, and then decays to the intrinsic sinus rate. Short-long prevention attempts to reduce short- long sequences as potential triggers of AF. The algorithm is triggered after a PAC, at which time an atrial paced beat is delivered to prevent a pause. Post-exercise response attempts to prevent the rapid drop in heart rate that may occur after exercise, which has been associated with initiation of AF. During exercise, the pacing rate increases to $90 \%$ of the physiologic rate. After exercise, the algorithm continues to pace at this rate and slowly decreases to the underlying sinus rate. Lastly, the Early Re-Initiation of Atrial Fibrillation (ERAF) suppression algorithms begin overdrive pacing after termination of the tachyarrhythmia, and gradually return to the underlying sinus rate[29].

There is some evidence for the efficacy of single algorithms in reducing symptomatic $\mathrm{AF}$, however there have been a greater number of trials looking at the efficacy of multiple concurrent AF prevention algorithms. Both of these can be grouped into trials that looked at AF patients with or without pre-existing bradycardia (Tables 1 and 2). Among patients with AF and bradycardia, the largest study to date is the SAFARI trial, which randomized patients with PAF and a standard indication for pacing to all algorithms on versus off. The primary endpoint was change in AF burden, defined as the average number of hours per day spent in atrial tachyarrhythmia. The algorithms in the on group included continuous pacing, PAC suppression, short-long prevention, post-exercise response, ERAF suppression, and ventricular rate stabilization. There was a significant decrease in AF burden in the algorithms on group, but no difference in AF frequency, average sinus rhythm duration, hospital admission, or rate of cardioversions $[30,31]$. Trials that include patients without a bradycardia indication have not shown the same reduction in AF burden (Table 2). Thus, AF prevention algorithms may have some use in decreasing AF burden for patients with prior bradycardia, but to date there is no evidence for benefit in patients without bradycardia.

\begin{tabular}{|c|c|c|c|c|c|}
\hline Trial & \# Patients & Inclusion criteria & Randomization arms & Follow-up & Results \\
\hline $\begin{array}{l}\text { A D O P T } \\
{[42]}\end{array}$ & $\begin{array}{l}319 \text { enrolled } \\
288 \text { analyzed }\end{array}$ & $\begin{array}{l}\geq 2 \text { AF episodes within } 1 \\
\text { month prior to implant, } \\
\text { sinus node dysfunction }\end{array}$ & $\begin{array}{l}\text { DDDR @60bpm with continuous } \\
\text { overdrive ON vs. OFF }\end{array}$ & 6 months & $\begin{array}{l}\text { Reduction in AF burden from } 2.5 \text { to } 1.87 \% \\
(\mathrm{p}=0.005) \text {. No difference in QOL or \# AF } \\
\text { episodes }\end{array}$ \\
\hline $\begin{array}{l}\text { Puglisi et } \\
\text { al.[43] }\end{array}$ & $\begin{array}{l}149 \text { enrolled } \\
98 \text { analyzed }\end{array}$ & $\begin{array}{l}1 \text { episode AT within } 6 \\
\text { months, bradycardia }\end{array}$ & $\begin{array}{l}\text { DDD@70bpm closed loop system vs. } \\
\text { DDD@70bpm with continuous over- } \\
\text { drive vs. DDDR@70bpm }\end{array}$ & 6 months & $\begin{array}{l}\text { Decreased AT burden in closed loop sys- } \\
\text { tem }(20.3 \mathrm{~min} / \mathrm{d}) \text { vs. overdrive }(56 \mathrm{~min} / \mathrm{d}) \text { or } \\
\operatorname{DDD}(63 \mathrm{~min} / \mathrm{d})(\mathrm{p}<0.01)\end{array}$ \\
\hline $\begin{array}{l}\text { PIRAT }[44] \\
3 / 4[45]\end{array}$ & $\begin{array}{l}70 \text { enrolled } \\
37 \text { analyzed }\end{array}$ & $\begin{array}{l}\text { Device-documented AT, } \\
\text { bradycardia }\end{array}$ & $\begin{array}{l}\text { DDDR + all therapies with ERAF sup- } \\
\text { pression ON vs OFF (atrial overdrive, } \\
\text { short-long prevention, burst+ATP, } \\
\text { ramp ATP active in both phases) }\end{array}$ & 3 months & $\begin{array}{l}\text { No difference in median number AT epi- } \\
\text { sodes, AT burden, \% ERAF, symptoms, or } \\
\text { QOL }\end{array}$ \\
\hline $3 / 4[45]$ & 107 & PAF, bradycardia & $\begin{array}{l}3 \text { triggered algorithms (PAC suppres- } \\
\text { sion, short-long prevention, post- } \\
\text { exercise response) vs. } 4 \text { ( } 3 \text { triggered + } \\
\text { continuous overdrive) }\end{array}$ & 3 months & $\begin{array}{l}\text { Decreased AF burden in } 3 \text { vs. } 4 \text { from ( } 5.1 \text { vs. } \\
12.7, p=0.026) \text {. Decreased AF episodes in } 3 \\
\text { vs. } 4 \text { ( } 405 \text { vs. } 621, p=0.05) \text {. }\end{array}$ \\
\hline $\begin{array}{l}\text { S A F A - } \\
\text { RI }[28]\end{array}$ & $\begin{array}{l}554 \text { enrolled } \\
187 \text { analyzed }\end{array}$ & AF, bradycardia & $\begin{array}{l}\text { All algorithms ON vs. OFF (continu- } \\
\text { ous overdrive, short-long prevention, } \\
\text { post-exercise response, PAC suppres- } \\
\text { sion, ERAF suppression, VRS) }\end{array}$ & 6 months & $\begin{array}{l}\text { Decrease in AF burden with algorithms ON } \\
\text { (decrease by } 0.11 \mathrm{~h} / \mathrm{d} \text { vs. increase of } 0.01 \text { in } \\
\text { OFF group). No difference AF frequency, } \\
\text { avg sinus duration, hospitalizations, or car- } \\
\text { dioversions. }\end{array}$ \\
\hline
\end{tabular}

Table 1: Trials evaluating pacing algorithms for prevention of AF (bradycardia indication required) 


\begin{tabular}{|c|c|c|c|c|c|}
\hline Trial & \# Patients & Inclusion criteria & Randomization arms & Follow-up & Results \\
\hline $\begin{array}{l}P \quad A \quad F- \\
P A C E[46]\end{array}$ & $\begin{array}{l}42 \text { enrolled } \\
35 \text { analyzed }\end{array}$ & $\begin{array}{l}\geq 2 \text { episodes/month dur- } \\
\text { ing prior } 3 \text { months }\end{array}$ & $\begin{array}{l}\text { No pacing vs. medium overdrive vs. } \\
\text { high overdrive pacing }\end{array}$ & $\begin{array}{l}\text { Variable de- } \\
\text { pending on } \\
\text { severity of } \\
\text { PAF }\end{array}$ & $\begin{array}{l}\text { Medium }(\mathrm{p}=0.01) \text { and high }(\mathrm{p}=0.002) \text { over- } \\
\text { drive pacing reduced symptomatic AF ver- } \\
\text { sus no pacing. }\end{array}$ \\
\hline PIPAF[47] & $\begin{array}{l}95 \text { enrolled } \\
55 \text { analyzed }\end{array}$ & $\begin{array}{l}\geq 1 \text { episode AF within } 3 \\
\text { months, } 49 \% \text { bradycardia }\end{array}$ & $\begin{array}{l}\text { DDDR@70bpm with algorithms ON } \\
\text { vs. OFF (atrial overdrive, short-long } \\
\text { prevention, PAC suppression) }\end{array}$ & 6 months & $\begin{array}{l}\text { No difference in AT duration, frequency, or } \\
\text { symptoms. Decrease in AT duration with } \\
\text { low ventricular pacing }(\mathrm{p}<0.04) \text { and de- } \\
\text { crease in AT number with increased atrial } \\
\text { pacing }(\mathrm{p}<0.03) \text {. }\end{array}$ \\
\hline PAFS[48] & $\begin{array}{l}182 \text { enrolled } \\
79 \text { analyzed }\end{array}$ & $\begin{array}{l}\geq 3 \text { AF episodes within } 1 \\
\text { month, AF burden } 1-50 \%\end{array}$ & $\begin{array}{l}\text { Atrial overdrive vs. VRS vs. atrial } \\
\text { overdrive + VRS + ERAF suppression } \\
\text { vs. OFF (DDR@60bpm) }\end{array}$ & 1 months & $\begin{array}{l}\text { No difference in AF burden. PAC triggered } \\
\text { AF reduced with atrial overdrive. }\end{array}$ \\
\hline
\end{tabular}

Table 2: Trials evaluating pacing algorithms for prevention of AF (bradycardia indication not required)

Alternative atrial site pacing: There has been significant interest in the potential benefits of alternative atrial site pacing to reduce the onset and burden of AF. There is some evidence that alternative pacing strategies may reduce dispersion of atrial refractoriness, increase cardiac output, and improve left atrial filling [32]. Proposed configurations consist of multi-site pacing and alternative single-site pacing. Multi-site pacing includes dual-site pacing in the right atrium and bi-atrial pacing. Dual-site right atrial pacing places one lead in the High Right Atrium (HRA) and one close to the Coronary Sinus ostium (CS os). Bi-atrial pacing uses one HRA lead and one CS lead for left atrial pacing. Alternative single-site pacing involves placement of a septal right atrial lead [29].

Thus far, none of the larger randomized trials have shown significant benefit for either multi-site or septal right atrial pacing in decreasing AF burden. For dual-site pacing, the DAPPAF trial randomized 118 patients with symptomatic PAF and bradycardia to control, HRA, or dual site pacing (HRA and CS os). There was no significant improvement in AF-free survival time, and while time to AF recurrence was significantly improved in dual-site versus control, the difference was not significant compared to HRA pacing [33]. The smaller NIPPAF trial showed a significant improvement in time to first AF recurrence with dual-site pacing and an overdrive algorithm versus standard single-site HRA pacing. However, it is unclear whether dual-site pacing or atrial overdrive was responsible for this benefit [34]. For bi-atrial pacing, the SYNBIAPACE study randomized patients with drug-resistant $A F$ to biatrial, right atrial appendage (RAA), and standard DDD pacing. There was a non-significant trend towards improved time to first recurrence of $\mathrm{AF}$ in the biatrial pacing group [35]. For alternative single-site pacing, the OASES and ASPECT trials investigated the effect of septal versus non-septal pacing, and various atrial pacing algorithms on or off, on AF burden. In both trials, there was no significant reduction in AF burden with pacing algorithms on in either septal or RAA groups [36,37].

In summary, AF prevention algorithms may have some benefit in improving AF burden, but this has mainly been demonstrated with multiple algorithms on and only in patients with pre-existing bradycardia. Alternative atrial site pacing may show some efficacy in improving time to first AF recurrence, but this has only been demonstrated in the setting of concurrent $\mathrm{AF}$ prevention algorithms. Currently, atrial pacing strate- gies do not exhibit sufficient clinical efficacy to employ them routinely in the treatment of AF.

\section{Role of pacemakers in monitoring AF}

Pacemaker diagnostics can provide information on the amount of AF, including the incidence of asymptomatic episodes (Figure 2). Atrial arrhythmias can be detected by mode switch or atrial high rate (AHR) episodes. Mode switch from dual chamber pacing (DDD) to a non-tracking mode (DDI or VVI) prevents rapid ventricular pacing during atrial tachyarrhythmias, and is triggered when an atrial arrhythmia meets a preset duration and rate. AHR counters with concurrent intracardiac electrograms provide even more information, often times allowing the clinician to distinguish among atrial tachyarrhythmias[29]. However, artifact or far field R wave oversensing can lead to inappropriate mode switch episodes (Figure 3). Some devices have a discrimination algorithm to distinguish far field $\mathrm{R}$ waves from true atrial arrhythmias, which allows devices to be programmed with a higher atrial sensitivity [38]. Intermittent undersensing still remains common, however, which significantly affects the accuracy of atrial arrhythmia detection (frequency and duration of episodes) (Figure 4).

Clinical Trends: 04/14/08-10/06/08 (Over Last 175 days) Last follow-up 06/10/08

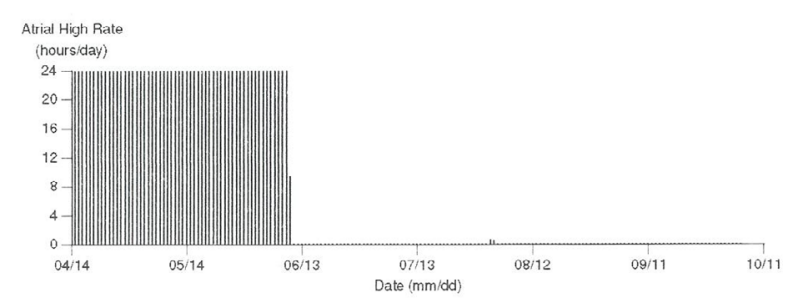

Figure 2: Stored histogram of atrial high rate episodes over a period of several months. Initially, AF is recorded by the device as occurring daily for approximately 24 hours per day. This is consistent with the patient history of persistent AF. After AF ablation, no further AF is recorded. This information is potentially useful in patient management. 


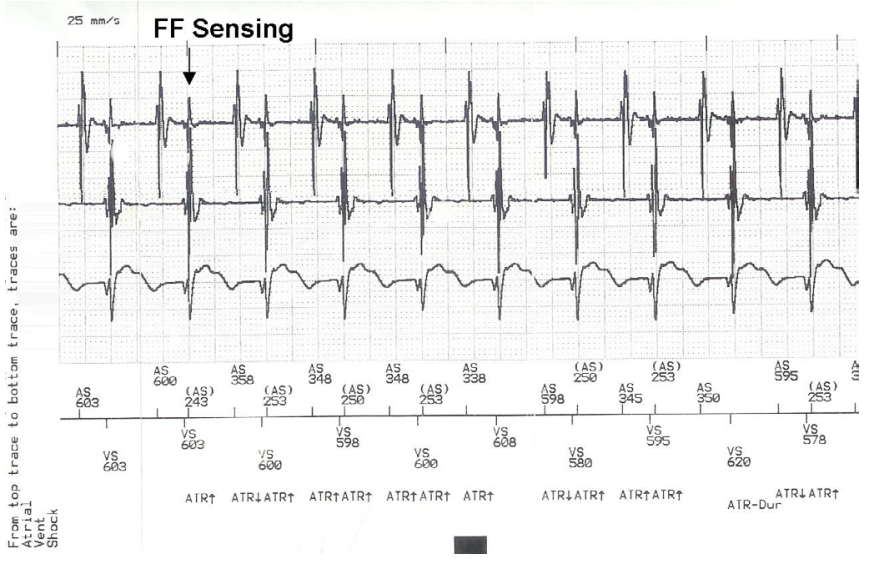

Figure 3: An example of far field over sensing on the atrial channel of a dual chamber device (arrow points to one example). Far field over sensing may result in false automatic mode switch or atrial high rate episodes. While programming the sensitivity may sometimes eliminate far field sensing, in this example the far field $\mathrm{R}$ wave is too large.

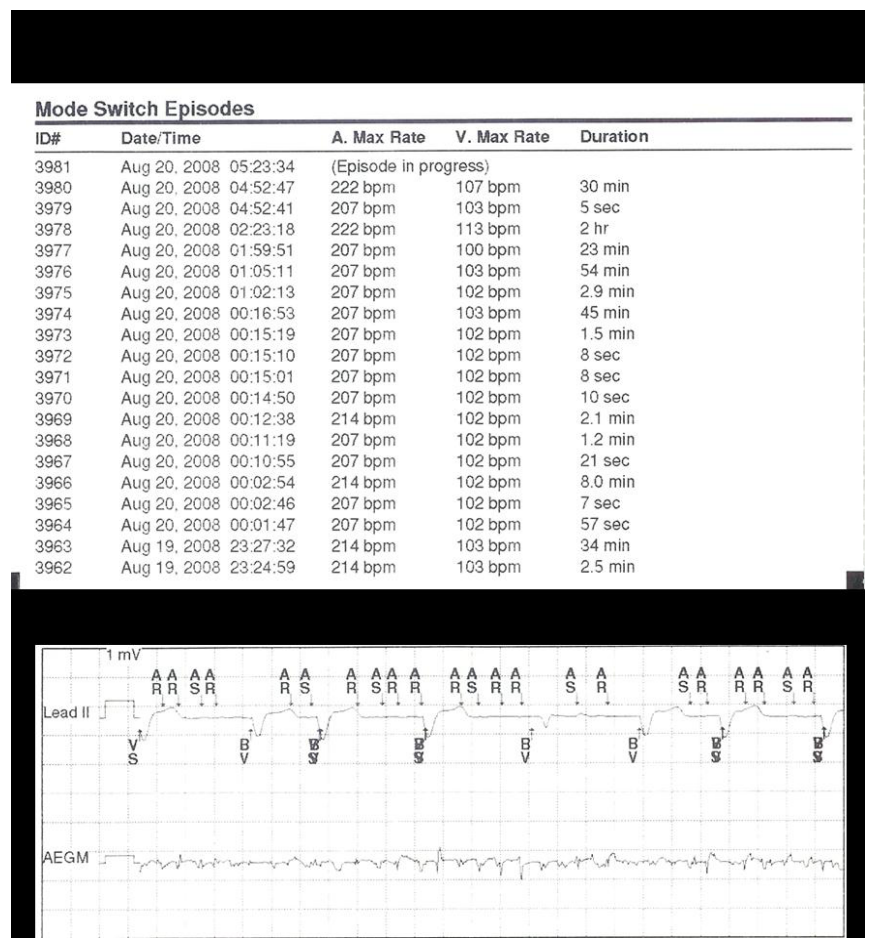

Figure 4: A) Pacemaker interrogation reveals multiple episodes of mode switch during a single day. This most likely represents a single episode of AF, with intermittent under sensing of atrial electrograms which results in counting multiple episodes rather than one. B) Atrial electrogram in atrial fibrillation. Note the irregular amplitude of the signals leading to intermittent under detection. This figure illustrates some of the challenges in utilizing the pacemaker to detect the amount of AF the patient is having.

Pacemaker diagnostics have shown that many atrial tachyarrhythmias are asymptomatic. Various studies have demonstrated that $93 \%$ of episodes 5 seconds or longer, $58 \%$ of episodes 1 minute or longer, and $38 \%$ of episodes 2 days or longer are asymptomatic [29]. Detection of AHR episodes is also correlated with a significantly greater risk of developing persistent AF, non-fatal stroke, and all-cause mortality [39].

The ASSERT trial looked at patients $\geq 65$ years with hypertension and an implanted device, but no history of AF, to see if detection of asymptomatic AHR episodes were associated with an increased risk of ischemic stroke or systemic embolism. They found that subclinical atrial arrhythmias were detected in $10.1 \%$ of patients and were associated with a significant increase in the primary outcomes during a 2.5 year follow-up period [40]. The ASSERT investigators also looked at whether Continuous Atrial Overdrive Pacing (CAOP) would prevent occurrence of symptomatic AF. Patients $\geq 65$ years without atrial fibrillation or stroke who were getting a new implanted device were randomized to CAOP on or off. They concluded that CAOP does not prevent new-onset AF, is poorly tolerated, and hastens battery depletion [41].

In general, pacemaker diagnostic information can be valuable but interpretation should be cautious, particularly when a change in therapy, such as the initiation of an anti-arrhythmic medication or anticoagulation, is contemplated. Undersensing of AF and oversensing of far field electrograms should also be considered when utilizing the device data. Often, confirmation of the rhythm using ambulatory monitoring may be useful.

\section{Summary}

While the pacemaker does not have a primary role in AF therapy, pacing as an adjunct therapy in patients with AF is an important one. Back-up pacing for patients with sinus node dysfunction or pacing after AV node ablation are valuable tools for the clinician in select patients. In addition, some patients may benefit from AF suppression algorithms and alternative atrial site pacing. Use of the pacemaker to "monitor" AF after medication changes or procedures may also be useful. The use of the pacemaker for heart rate support, algorithms, or diagnostics should be tailored to the patient based on clinical history and selected therapy for AF.

\section{References}

1) Wood MA, Brown-Mahoney C, Kay GN, Ellenbogen KA (2000) Clinical outcomes after ablation and pacing therapy for atrial fibrillation: a meta-analysis. Circulation 101: 1138-1144.

2) Ozcan C, Jahangir A, Friedman PA, Munger TM, Packer DL, et al. (2003) Significant effects of atrioventricular node ablation and pacemaker implantation on left ventricular function and long-term survival in patients with atrial fibrillation and left ventricular dysfunction. Am J Cardiol 92: 33-37.

3) Kalahasty G, Ellenbogen K (2008) The role of pacemakers in the management of patients with atrial fibrillation. Med Clin North Am 92: 161-178.

4) Touboul $P$ (1999) Atrioventricular nodal ablation and pacemaker implantation in patients with atrial fibrillation. Am J Cardiol 83: 241D-245D.

5) Weinstock J, Wang PJ, Homoud MK, Link MS, Estes NA 3rd (2003) Clinical results with catheter ablation: AV junction, atrial fibrillation and ventricular tachycardia. J Interv Card Electrophysiol, 9: 275-288.

6) Brignole M, Gianfranchi L, Menozzi C, Bottoni N, Bollini R, et al. (1994) Influence of atrioventricular junction radiofrequency ablation in patients with chronic atrial fibrillation and flutter on quality of life and cardiac performance. Am J Cardiol 74: 242-246.

7) Brignole M, Menozzi C, Gianfranchi L, Musso G, Mureddu R, et al. (1998) Assessment of atrioventricular junction ablation and VVIR pacemaker versus pharmacological treatment in patients with heart failure and chronic atrial fibrillation: a randomized, controlled study. Circulation. 98: 953-960.

8) Brignole M, Gianfranchi L, Menozzi C, Alboni P, Musso G, et al. (1997) Assessment of atrioventricular junction ablation and DDDR mode-switching pacemaker versus pharmacological treatment in patients with severely symptomatic paroxysmal atrial fibrillation: a randomized controlled study. Circulation 96: 2617-2624. 
9) Marshall HJ, Harris ZI, Griffith MJ, Holder RL, Gammage MD (1999) Prospective randomized study of ablation and pacing versus medical therapy for paroxysmal atrial fibrillation: effects of pacing mode and mode-switch algorithm. Circulation 99: 1587-1592.

10) Stevenson WG, Tedrow U (2007) Management of atrial fibrillation in patients with heart failure. Heart Rhythm 4: S28-S30.

11) Doshi RN, Daoud EG, Fellows C, Turk K, Duran A, et al. (2005) Left ventricular-based cardiac stimulation post $\mathrm{AV}$ nodal ablation evaluation (the PAVE study). J Cardiovasc Electrophysiol 16: 1160-1165.

12) Hamdan MH, Freedman RA, Gilbert EM, Dimarco JP, Ellenbogen KA, et al. (2006) Atrioventricular junction ablation followed by resynchronization therapy in patients with congestive heart failure and atrial fibrillation (AVERT-AF) study design. Pacing Clin Electrophysiol 29: 1081-1088.

13) Curtis AB, Worley SJ, Adamson PB, Chung ES, Niazi I, et al. (2013) Biventricular pacing for atrioventricular block and systolic dysfunction. $\mathrm{N}$ Engl J Med 368: 1585-1593.

14) Khan MN, Jaïs P, Cummings J, Di Biase L, Sanders P, et al. (2008) Pulmonary-vein isolation for atrial fibrillation in patients with heart failure. N Engl J Med 359: 1778-1785.

15) Ozcan C, Jahangir A, Friedman PA, Patel PJ, Munger TM, et al. (2001) Long-term survival after ablation of the atrioventricular node and implantation of a permanent pacemaker in patients with atrial fibrillation. $\mathrm{N}$ Engl J Med 344: 1043-1051.

16) Wood MA (2004) Trials of pacing to control ventricular rate during atrial fibrillation. J Interv Card Electrophysiol 10: 63-70.

17) Clark DM, Plumb VJ, Epstein AE, Kay GN (1997) Hemodynamic effects of an irregular sequence of ventricular cycle lengths during atrial fibrillation. J Am Coll Cardiol 30: 1039-1045.

18) Daoud EG, Weiss R, Bahu M, Knight BP, Bogun F, et al. (1996) Effect of an irregular ventricular rhythm on cardiac output. Am J Cardiol 78: 1433-1436.

19) Wittkampf FH, de Jongste MJ, Lie HI, Meijler FL (1988) Effect of right ventricular pacing on ventricular rhythm during atrial fibrillation. J Am Coll Cardiol 11: 539-545.

20) Lian J, Müssig D, Lang V (2007) Ventricular rate smoothing for atrial fibrillation: a quantitative comparison study. Europace 9: 506-513.

21) Simpson CS, Yee R, Lee JK, Braney M, Klein GJ, et al. (2001) Safety and feasibility of a novel rate-smoothed ventricular pacing algorithm for atrial fibrillation. Am Heart J 142: 294-300.

22) Tse HF, Newman D, Ellenbogen KA, Buhr T, Markowitz T, et al. (2004) Effects of ventricular rate regularization pacing on quality of life and symptoms in patients with atrial fibrillation (Atrial fibrillation symptoms mediated by pacing to mean rates [AF SYMPTOMS study]). Am J Cardiol 94: 938-941.

23) Verma A, Newman D, Geist M, Greenhut S, Laslop J, et al. (2001) Effects of rhythm regularization and rate control in improving left ventricular function in atrial fibrillation patients undergoing atrioventricular nodal ablation. Can J Cardiol 17: 437-445.

24) Lau CP, Jiang ZY, Tang MO (1998) Efficacy of ventricular rate stabilization by right ventricular pacing during atrial fibrillation. Pacing Clin Electrophysiol 21: 542-548.

25) Duckers HJ, van Hemel NM, Kelder JC, Bakema H, Yee R (1997) Effective use of a novel rate-smoothing algorithm in atrial fibrillation by ventricular pacing. Eur Heart J 18: 1951-1955.

26) Tse HF, Wong KK, Siu CW, Tang MO, Tsang V, et al. (2009) Impacts of ventricular rate regularization pacing at right ventricular apical vs. septal sites on left ventricular function and exercise capacity in patients with permanent atrial fibrillation. Europace 11: 594-600.

27) Tse HF, Siu CW, Lau CP (2009) Impact of right ventricular pacing sites on exercise capacity during ventricular rate regularization patients with permanent atrial fibrillation. Pacing Clin Electrophysiol 32: 1536-1542.

28) Popovic ZB, Mowrey KA, Zhang Y, Zhuang S, Tabata T, et al. (2002) Slow rate during $\mathrm{AF}$ improves ventricular performance by reducing sensitivity to cycle length irregularity. Am J Physiol Heart Circ Physiol 283: H2706-H2713.

29) Silberbauer J, Sulke N (2007) The role of pacing in rhythm control and management of atrial fibrillation. J Interv Card Electrophysiol 18: 159-186.
30) Gold MR, Hoffmann E (2006) Rationale and design of a randomized clinical trial to assess the role of overdrive and triggered prevention pacing therapies in reducing atrial fibrillation: the Study of Atrial Fibrillation Reduction (SAFARI). Am Heart J 152: 231-236.

31) Gold MR, Adler S, Fauchier L, Haffajee C, Ip J, et al. (2009) Impact of atrial prevention pacing on atrial fibrillation burden: primary results of the Study of Atrial Fibrillation Reduction (SAFARI) trial. Heart Rhythm 6: 295-301.

32) Prakash A, Saksena S, Hill M, Krol RB, Munsif AN, et al. (1997) Acute effects of dual-site right atrial pacing in patients with spontaneous and inducible atrial flutter and fibrillation. J Am Coll Cardiol 29: 1007-1014.

33) Saksena S, Prakash A, Ziegler P, Hummel JD, Friedman P, et al. (2002) Improved suppression of recurrent atrial fibrillation with dual-site right atrial pacing and antiarrhythmic drug therapy. J Am Coll Cardiol 40: 1140-1150

34) Lau CP, Tse HF, Yu CM, Teo WS, Kam R, et al. (2001) Dual-site atrial pacing for atrial fibrillation in patients without bradycardia. Am J Cardiol 88: 371-375.

35) Padeletti L, Pürerfellner H, Adler SW, Waller TJ, Harvey M, et al. (2003) Combined efficacy of atrial septal lead placement and atrial pacing algorithms for prevention of paroxysmal atrial tachyarrhythmia. J Cardiovasc Electrophysiol 14: 1189-1195.

36) Willem de Voogt, Norbert van Hemel, Philip de Vusser, Georges H Mairesse, Rob van Mechelen, et al. (2007) No evidence of automatic atrial overdrive pacing efficacy on reduction of paroxysmal atrial fibrillation. Europace 9: 798-804.

37) Israel CW, Barold SS (2001) Pacemaker systems as implantable cardiac rhythm monitors. Am J Cardiol 88: 442-445.

38) Glotzer TV, Hellkamp AS, Zimmerman J, Sweeney MO, Yee R, et al. (2003) Atrial high rate episodes detected by pacemaker diagnostics predict death and stroke: report of the Atrial Diagnostics Ancillary Study of the MOde Selection Trial (MOST). Circulation 107: 1614-1619.

39) Healey JS, Connolly SJ, Gold MR, Israel CW, Van Gelder IC, et al. (2012) Subclinical atrial fibrillation and the risk of stroke. N Engl J Med 366: 120-129.

40) Hohnloser SH, Healey JS, Gold MR, Israel CW, Yang S, et al. (2012) Atrial overdrive pacing to prevent atrial fibrillation: insights from ASSERT. Heart Rhythm 9: 1667-1673.

41) Carlson MD, Ip J, Messenger J, Beau S, Kalbfleisch S, et al. (2003) A new pacemaker algorithm for the treatment of atrial fibrillation: results of the Atrial Dynamic Overdrive Pacing Trial (ADOPT). J Am Coll Cardiol 42: 627-633. 42) Puglisi A, Altamura G, Capestro F, Castaldi B, Critelli G, et al. (2003) Impact of Closed-Loop Stimulation, overdrive pacing, DDDR pacing mode on atrial tachyarrhythmia burden in Brady-Tachy Syndrome. A randomized study. Eur Heart J 24: 1952-1961.

43) Israel CW, Grönefeld G, Ehrlich JR, Li YG, Hohnloser SH (2003) Prevention of immediate reinitiation of atrial tachyarrhythmias by high-rate overdrive pacing: results from a prospective randomized trial. J Cardiovasc Electrophysiol 14: 954-959.

44) Schuchert A, Bub E, Braun M, Rebeski HP, Kroll W, et al. (2004) Comparison of triggered versus triggered and continuous atrial overdrive pacing on AF burden in pacemaker patients with paroxysmal atrial fibrillation. Heart Rhythm 1: 866.

45) Wiberg S, Lönnerholm S, Jensen SM, Blomström P, Ringqvist I, et al. (2003) Effect of right atrial overdrive pacing in the prevention of symptomatic paroxysmal atrial fibrillation: a multicenter randomized study, the PAF-PACE study. Pacing Clin Electrophysiol 26: 1841-1848.

46) Blanc JJ, De Roy L, Mansourati J, Poezevara Y, Marcon JL, et al. (2004) Atrial pacing for prevention of atrial fibrillation: assessment of simultaneously implemented algorithms. Europace 6: 371-379.

47) Sulke N, Silberbauer J, Boodhoo L, Freemantle N, Kamalvand K, et al. (2007) The use of atrial overdrive and ventricular rate stabilization pacing algorithms for the prevention and treatment of paroxysmal atrial fibrillation: the Pacemaker Atrial Fibrillation Suppression (PAFS) study. Europace 9: 790797. 